\title{
Endobronchial coil treatment in severe emphysema patients with alpha-I antitrypsin deficiency
}

This article was published in the following Dove Press journal: International Journal of COPD

Jeanne Marie Perotin, ' Sylvie Leroy, ${ }^{2}$ Charles Hugo Marquette, ${ }^{2}$ Hervé Mal, ${ }^{3}$ Hervé Dutau, ${ }^{4}$ Arnaud Bourdin, ${ }^{5}$ Jean Michel Vergnon, ${ }^{6}$ Christophe Pison, ${ }^{7}$ Coralie Barbe, ${ }^{8}$ Gaëtan Deslee'

On behalf of the REVOLENS Study Group

'Service de Pneumologie, INSERM UI 250, Hôpital Universitaire, Reims, France; ${ }^{2}$ Service de Pneumologie, $\mathrm{CHU}$ de Nice, FHU OncoAge, Université Côte d'Azur, Nice, France; ${ }^{3}$ Service de Pneumologie, Hôpital Universitaire Bichat, Paris, France; ${ }^{4}$ Service d'Oncologie Thoracique, Maladies de la Plèvre, Pneumologie Interventionnelle, Hôpital Universitaire, Marseille, France; ${ }^{5}$ Département de Pneumologie et Addictologie, PhyMedExp, INSERM UI046, CNRS UMR, Hôpital Universitaire, Montpellier, France; ${ }^{6}$ Service de Pneumologie, Hôpital Universitaire, Saint Etienne, France; ${ }^{7} \mathrm{Clinique}$ Universitaire de Pneumologie, Pôle Thorax et Vaisseaux, Inserm I 055, Hôpital Universitaire Grenoble Alpes, Université Grenoble Alpes, Grenoble, France; ${ }^{8}$ Département de Méthodologie, Pôle RechercheInnovations, Hôpital Universitaire, Reims, France

Correspondence: Gaëtan Deslee Service de Pneumologie, INSERM UI250, Hôpital Universitaire, 45 rue CognacqJay, 5 I 100 Reims, France

Tel +33 32678761 I

Fax +33 328798356

Email gdeslee@chu-reims.fr
Abstract: Endobronchial coil treatment (ECT) is a minimally invasive procedure developed for palliative care of patients with severe emphysema. ECT has demonstrated a decrease in hyperinflation, an improvement in quality of life, and an acceptable safety profile in randomized controlled trials (RCTs). Because alpha-1 antitrypsin deficiency (AATD) is a classical exclusion criterion in RCTs, there is no available data for ECT in AATD. In this post hoc analysis of the REVOLENS study (Réduction volumique endobronchique par spirales; ClinicalTrials.gov Identifier: NCT01822795), a multicenter 1:1 RCT which compared bilateral ECT with usual care in severe emphysema, we analyzed the efficacy and safety results at 1 year in six patients with AATD (five males, one female; mean age: $52 \pm 9$ years) who underwent ECT. A significant decrease in hyperinflation $(0.35 \mathrm{~L}$ decrease in residual volume [RV]) was observed in four out of six patients at 6 months and three out of six patients at 12 months, and an improvement in quality of life (improvement of 4 points in the St George's Respiratory Questionnaire [SGRQ]) was observed in four out of six patients at both 6 and 12 months. Efficacy results at 6 and 12 months from the six AATD patients were compared with 84 non-AATD patients who underwent ECT, and no statistically significant differences were found for FEV, RV, 6MWT score and SGRQ score. Respiratory-related serious adverse event was limited to pneumonia in one AATD patient at 1 year post-ECT. This post hoc study suggests that AATD patients may have similar efficacy and safety outcomes at 1 year as non-AATD patients. Because of the paucity of available data, appropriately powered studies are needed to determine the effects of ECT in AATD.

Keywords: COPD, volume reduction, interventional, bronchoscopy

\section{Introduction}

Despite optimal medical management including intravenous alpha-1 antitrypsin (AAT) augmentation therapy, many patients with AAT deficiency (AATD) with severe emphysema remain symptomatic. ${ }^{1}$ Compared with non-AATD-related emphysema, lung volume reduction surgery is associated with inferior outcomes and lung transplantation is associated with similar outcomes in AATD emphysema. ${ }^{2}$ Endobronchial lung volume reduction (ELVR) treatments including valves, coils, and thermal vapor ablation have demonstrated efficacy and safety in randomized controlled trials (RCTs) including highly selected emphysematous patients. ${ }^{3}$ However, AATD emphysema is a usual exclusion criterion in RCTs, which has led to the absence of robust data in this population. The REVOLENS study (Réduction volumique endobronchique par spirales; ClinicalTrials.gov Identifier: NCT01822795) is the only one RCT which included AATD patients. In this post hoc analysis of the REVOLENS study, we specifically analyzed the 1-year efficacy and safety outcomes of endobronchial coil treatment $(\mathrm{ECT})$ in AATD patients. 


\section{Methods}

REVOLENS is a multicenter 1:1 RCT which compared bilateral coil treatment with usual care in 100 patients with severe emphysema, and showed a decrease in hyperinflation, an improvement in quality of life, and an acceptable safety profile at 1 year. ${ }^{4}$ The main inclusion criteria in the REVOLENS study were bilateral emphysema, $\mathrm{FEV}_{1}$ of less than $50 \%$ predicted, residual volume (RV) of $>220 \%$ predicted, and pulmonary rehabilitation in the previous year. ${ }^{4}$ AATD was not an exclusion criterion. Patients randomized to the coil group received bilateral coil treatment in two sequential procedures. The most severely affected lobe of each lung was determined by each investigator using a visual score from 0 to 4 . Coils were placed in the most affected lobe, with the upper lobe chosen when visual ipsilateral scores were the same. All patients had a 1-year follow-up, and patients in the usual care group were proposed ECT after the 1-year visit (cross-over group) with subsequent prespecified assessments at 6 and 12 months. AATD was defined by a PiZZ phenotype and a serum AAT level of less than $0.5 \mathrm{~g} / \mathrm{L}$.

In this post hoc analysis, we analyzed the safety and efficacy outcomes of all AATD patients who underwent ECT in the first phase or in the cross-over period, with end points at 6 months and 1 year after coil treatment.

The study was approved by the Ethics Committee of Dijon Est I (N²012-A01477-36) and the French National Agency for Medicines and Health Products Safety (ANSM). Each patient signed a written informed consent.

Variables are presented as median [range] and percentages. Differences in efficacy and safety outcomes between AATD and non-AATD patients were analyzed using Wilcoxon tests for quantitative variables and Fisher's exact tests for qualitative variables, with no data imputation. A $P$-value $<0.05$ was considered as significant.

\section{Case series}

Among 100 patients included in the REVOLENS study, three AATD patients were randomized to the coil group and four AATD patients to the usual care group. One AATD patient randomized to the usual care group was not subjected to ECT after 1 year because of anticoagulation therapy for atrial fibrillation and active smoking. The remaining six AATD patients (five males, one female; mean age: $52 \pm 9$ years) underwent bilateral ECT and were included in this post hoc analysis. Among these six patients, four received AAT augmentation therapy which was started before ECT. ECT was performed in the right upper lobe $(\mathrm{n}=3)$, left upper lobe $(n=4)$, right lower lobe $(n=3)$, and left lower lobe $(n=2)$, with a median of 10 [8;12] coils per lobe. Baseline, 6-month changes, and 12-month changes in $\mathrm{FEV}_{1}, \mathrm{RV}, 6 \mathrm{MWT}$ score, and quality of life assessed by the St George's Respiratory Questionnaire (SGRQ) are shown in Table 1. Significant improvement in hyperinflation defined by a minimal clinically important difference (MCID) of $0.35 \mathrm{~L}$ decrease in $\mathrm{RV}^{5}$ was observed in four out of six patients at 6 months and three out of six patients at 12 months. Significant improvement in quality of life defined by an MCID of 4 points in the SGRQ ${ }^{6}$ was observed in four out of six patients at both 6 and 12 months. One patient (case 4) exhibited a significant decrease in hyperinflation, whereas the quality of life did not improve. Of note, this patient had two serious adverse events (SAEs) and five non-SAEs within the 1-year follow-up, which included one pneumonia and four COPD exacerbations, which may explain the absence of response in terms of quality of life.

In an exploratory post hoc analysis, efficacy results at 6 and 12 months from the six AATD patients were compared with those from 84 non-AATD patients treated by coils in the REVOLENS study. This analysis suggested similar efficacy outcomes in AATD and non-AATD patients at 6 and 12 months with no difference in $\mathrm{FEV}_{1}, \mathrm{RV}, 6 \mathrm{MWT}$ score, and SGRQ score (Table 2). SAEs and non-SAEs within 1 year in the six AATD patients who underwent ECT are shown in Table 1. Respiratory-related SAE was limited to pneumonia in one AATD patient. By comparison, SAEs within 1 year after ECT in the 84 non-AATD patients included deaths (five cases), pneumothorax (seven cases), COPD exacerbations (21 cases), pneumonia (16 cases), thoracic pain (four cases), hemoptysis (two cases) requiring hospitalization, and other causes (18 cases). When compared to non-AATD patients, the rates of SAEs and non-SAEs at 1 year in the six AATD patients were not statistically different (not shown).

\section{Discussion}

To our knowledge, this is the first study reporting efficacy and safety outcomes in AATD patients who underwent ECT. Our results suggest that ECT in AATD patients might be associated with a decrease in hyperinflation, an improvement in quality of life, and an acceptable safety profile at 1 year. However, our results must be interpreted with caution because of significant limitations. First, only six AATD patients were treated with coils in this study, leading to consider the present post hoc analysis as underpowered and exploratory, especially for comparisons with the non-AATD group. Second, only four out of six AATD patients received intravenous augmentation therapy. However, the impact of AAT augmentation therapy on our results should not be considered as a confounding factor because AAT augmentation 
Table I Characteristics, coil treatment, changes at 6 and 12 months, and I-year adverse events in AATD patients included in the REVOLENS study

\begin{tabular}{|c|c|c|c|c|c|c|}
\hline Variable & Case I & Case 2 & Case 3 & Case 4 & Case 5 & Case 6 \\
\hline Age (years), sex (M/F) & $48, M$ & $57, \mathrm{~F}$ & $39, M$ & $64, M$ & $47, M$ & $61, M$ \\
\hline BMI $\left(\mathrm{kg} \cdot \mathrm{m}^{-2}\right)$ & 23.7 & 20.3 & 27.8 & 24.1 & 25.1 & 21.8 \\
\hline Pack-years smoking & 26 & 24 & 20 & 40 & 16 & 15 \\
\hline Augmentation therapy & No & Yes & No & Yes & Yes & Yes \\
\hline $\begin{array}{l}\text { Lobe, } \mathrm{n} \text { coils } \\
\text { First } \\
\text { Second }\end{array}$ & $\begin{array}{l}\text { RLL, } 12 \\
\text { LLL, } 10\end{array}$ & $\begin{array}{l}\text { RLL, } 10 \\
\text { LUL, I2 }\end{array}$ & $\begin{array}{l}\text { RLL, I0 } \\
\text { LLL, II }\end{array}$ & $\begin{array}{l}\text { RUL, } 12 \\
\text { LUL, } 10\end{array}$ & $\begin{array}{l}\text { RUL, I0 } \\
\text { LUL, } 10\end{array}$ & $\begin{array}{l}\text { RUL, I0 } \\
\text { LUL, } 9\end{array}$ \\
\hline $\begin{array}{l}\mathrm{FEV}_{1}, \mathrm{~L}(\%) \\
\text { Changes at } 6 \mathrm{Mo}, \mathrm{L} \\
\text { Changes at } \mathrm{I} 2 \mathrm{Mo}, \mathrm{L}\end{array}$ & $\begin{array}{l}0.68(18) \\
-0.05 \\
-0.02\end{array}$ & $\begin{array}{l}0.82(32) \\
+0.06 \\
-0.13\end{array}$ & $\begin{array}{l}\text { I.22(29) } \\
-0.25 \\
-0.23\end{array}$ & $\begin{array}{l}0.62(20) \\
+0.28 \\
+0.26\end{array}$ & $\begin{array}{l}0.96(25) \\
+0.08 \\
-0.09\end{array}$ & $\begin{array}{l}0.81(26) \\
-0.01 \\
-0.07\end{array}$ \\
\hline $\begin{array}{l}\text { RV, } \mathrm{L}(\%) \\
\text { Changes at } 6 \mathrm{Mo}, \mathrm{L} \\
\text { Changes at } \mathrm{I} 2 \mathrm{Mo}, \mathrm{L}\end{array}$ & $\begin{array}{l}6.51(304) \\
-0.42 \\
-0.63\end{array}$ & $\begin{array}{l}5.44(284) \\
+0.76 \\
-0.32\end{array}$ & $\begin{array}{l}5.68(284) \\
-0.5 \\
+0.62 \\
\end{array}$ & $\begin{array}{l}7.29(300) \\
-2.42 \\
-1.09\end{array}$ & $\begin{array}{l}6.2(299) \\
-0.04 \\
-0.04\end{array}$ & $\begin{array}{l}5.94(256) \\
-0.45 \\
-0.47\end{array}$ \\
\hline $\begin{array}{l}\text { 6MWT, m } \\
\text { Changes at } 6 \mathrm{Mo}, \mathrm{m} \\
\text { Changes at } 12 \mathrm{Mo}, \mathrm{m}\end{array}$ & $\begin{array}{l}433 \\
-31 \\
-39\end{array}$ & $\begin{array}{l}423 \\
-3 \\
-13\end{array}$ & $\begin{array}{l}482 \\
+6 \\
+49\end{array}$ & $\begin{array}{l}108 \\
+102 \\
-48\end{array}$ & $\begin{array}{l}420 \\
0 \\
0\end{array}$ & $\begin{array}{l}264 \\
-114 \\
-24\end{array}$ \\
\hline $\begin{array}{l}\text { SGRQ, points } \\
\text { Changes at } 6 \mathrm{Mo}, \mathrm{L} \\
\text { Changes at } \mathrm{I} 2 \mathrm{Mo}, \mathrm{L}\end{array}$ & $\begin{array}{l}48 \\
-10 \\
-10\end{array}$ & $\begin{array}{l}39 \\
-2 \\
-2\end{array}$ & $\begin{array}{l}25 \\
-6 \\
-6\end{array}$ & $\begin{array}{l}88 \\
+1 \\
+2\end{array}$ & $\begin{array}{l}47 \\
-6 \\
-5\end{array}$ & $\begin{array}{l}62 \\
-9 \\
-11\end{array}$ \\
\hline $\begin{array}{l}\text { SAEs (in I year) } \\
\text { Pneumonia } \\
\text { Other }\end{array}$ & 0 & 0 & 0 & $\begin{array}{l}2 \\
\mathrm{I}^{\mathrm{a}} \\
\mathrm{I}^{\mathrm{b}}\end{array}$ & 0 & 0 \\
\hline $\begin{array}{l}\text { Non-SAEs (in I year) } \\
\text { COPD exacerbation } \\
\text { Pneumonia } \\
\text { Mild hemoptysis } \\
\text { Other respiratory } \\
\text { Non-respiratory }\end{array}$ & $\begin{array}{l}3 \\
1 \\
0 \\
0 \\
1 \\
1\end{array}$ & $\begin{array}{l}6 \\
3 \\
0 \\
0 \\
3 \\
0\end{array}$ & $\begin{array}{l}0 \\
0 \\
0 \\
0 \\
0 \\
0\end{array}$ & $\begin{array}{l}5 \\
4 \\
0 \\
0 \\
1 \\
0\end{array}$ & $\begin{array}{l}12 \\
4 \\
2 \\
2 \\
1 \\
3\end{array}$ & $\begin{array}{l}3 \\
2 \\
0 \\
1 \\
0 \\
0\end{array}$ \\
\hline
\end{tabular}

Notes: aPneumonia 6 days after the first coil treatment resolving with antibiotics and corticosteroids. ${ }^{\circ}$ One colonoscopy requiring hospitalization.

Abbreviations: AATD, alpha-I antitrypsin deficiency; BMI, body mass index; F, female; LLL, left lower lobe; LUL, left upper lobe; M, male; Mo, months; RLL, right lower lobe; RUL, right upper lobe; RV, residual volume; SAEs, serious adverse events; SGRQ, St George's Respiratory Questionnaire.

therapy was started before ECT and maintained during the 1-year follow-up, and AAT augmentation therapy was not associated with significant changes at 1 year in $\mathrm{FEV}_{1}, \mathrm{RV}$, 6MWT score, and SGRQ score. ${ }^{7}$ Another limitation is the lack of assessment by computed tomography scan of the lobar volume changes induced by ECT.

The present case series suggests that the positive effects of ECT in AATD patients are mainly represented by a

Table 2 Efficacy end points in AATD patients included in the REVOLENS study

\begin{tabular}{|c|c|c|c|}
\hline Changes from baseline $^{a}$ & $\begin{array}{l}\text { Alpha-I antitrypsin } \\
\text { patients }(n=6)\end{array}$ & $\begin{array}{l}\text { Other patients } \\
(n=84)\end{array}$ & $P$-value \\
\hline \multicolumn{4}{|l|}{6 months } \\
\hline 6MWT, m & $-2[-114 ;+102]$ & $+I[-224 ;+205]$ & $0.60^{\mathrm{b}}$ \\
\hline $\mathrm{FEV}_{1}, \mathrm{~L}$ & $+0.03[-0.25 ;+0.28]$ & $+0.03[-0.28 ;+0.59]$ & $0.87^{\mathrm{b}}$ \\
\hline $\mathrm{RV}, \mathrm{L}$ & $-0.44[-2.42 ;+0.76]$ & $-0.39[-2.5 \mathrm{I} ;+\mathrm{I} .4 \mathrm{I}]$ & $0.89^{b}$ \\
\hline SGRQ total & $-6[-10 ;+1]$ & $-8[-47 ;+35]$ & $0.59^{\mathrm{b}}$ \\
\hline \multicolumn{4}{|l|}{12 months } \\
\hline 6MWT, m & $-19[-48 ;+49]$ & $0[-200 ;+188]$ & $0.57^{\mathrm{b}}$ \\
\hline $\mathrm{FEV}_{1}, \mathrm{~L}$ & $-0.08[-0.23 ;+0.26]$ & $+0.02[-0.37 ;+0.59]$ & $0.10^{\mathrm{b}}$ \\
\hline $\mathrm{RV}, \mathrm{L}$ & $-0.40[-1.09 ;+0.62]$ & $-0.4 \mathrm{I}[-2.77 ;+2.45]$ & $0.85^{\mathrm{b}}$ \\
\hline SGRQ total & $-6[-11 ;+2]$ & $-5[-47 ;+32]$ & $0.99^{\mathrm{b}}$ \\
\hline
\end{tabular}

Notes: ${ }^{a}$ Data are expressed as median [range]. bWilcoxon test.

Abbreviations: AATD, alpha-I antitrypsin deficiency; RV, residual volume; SGRQ, St George's Respiratory Questionnaire. 
decrease in hyperinflation and an improvement in quality of life, whereas changes in $\mathrm{FEV}_{1}$ and 6MWT score are mild and do not reach the MCID for most of the AATD patients. The other important point to consider is that only one respiratoryrelated SAE occurred within 1 year after ECT in one of the six AATD patients, suggesting the safety of ECT in AATD patients. Because of the significant limitations of this post hoc analysis, additional studies are clearly needed to determine the efficacy and safety of ECT in AATD patients. So far, available data regarding the safety and efficacy of ELVR in AATD are limited to endobronchial valves with one retrospective monocentric study including 15 consecutive AATD patients among which 12 patients were assessed at 1 year $^{8}$ and one prospective study including six AATD patients with a mean duration of follow-up of 8 months, ${ }^{9}$ both showing significant improvements in $\mathrm{FEV}_{1}$.

In conclusion, this post hoc analysis of the REVOLENS study suggests that AATD patients with severe emphysema may have similar efficacy and safety outcomes at 1 year after ECT as non-AATD-related emphysema. Because of the paucity of available data, these results advocate for conducting appropriately powered studies to assess the effects of ECT in AATD.

\section{Data and safety management board}

The data and safety management board members include François Fourrier MD PhD, Eric Hachulla MD PhD, Nicolas Roche MD PhD, and Daniel Dusser MD PhD. These collaborators did not receive any compensation for their contribution.

\section{Acknowledgments}

The members of the REVOLENS Study Group include all authors and Hervé Vallerand MD, François Lebargy MD PhD, Sandra Dury MD, Claire Launois MD (Hôpital Universitaire de Reims), Johanna Pradelli MD, Matthieu Buscot MD, Celine Sanfiorenzo MD, Sylvie Korzeniewski MD, Andrea Mazzetta MD, Jennifer Griffonnet, Ariane Guillemart, Demosthenes Makris MD (Hôpital Universitaire de Nice), Armelle Marceau MD, Marie Christine Dombret MD, Frédérique Servin MD, Marie Pierre Debray MD (Hôpital Universitaire Bichat, Paris), Sophie Laroumagne MD, Fabienne Bregeon MD PhD, Carine Gomez MD, Philippe Astoul MD PhD (Hôpital Universitaire de Marseille), Nathalie Lesavre MD (Center d'Investigation Clinique 1409, AP-HM, Marseille), Jean Pierre Mallet MD, Anne Sophie Gamez MD, Philippe Tarodo MD, Christophe Brousse MD, Clément Broissin MD (Hôpital Universitaire de Montpellier), Yoann Thibout MD,
Fabrice Di Palma MD, Frédéric Costes MD (Hôpital Universitaire de Saint Etienne), Amandine Briault MD, François Arbib MD, Emilie Reymond MD (Hôpital Universitaire de Grenoble), Romain Kessler MD PhD, Michele Porzio MD, Benjamin Renaud-Picard MD (Hôpital Universitaire de Strasbourg), Vincent Jounieaux MD PhD, Bénédicte Toublanc MD, Géraldine François MD (Hôpital Universitaire d'Amiens), Mathieu Salaün MD PhD, Luc Thiberville, MD $\mathrm{PhD}$, Antoine Cuvelier MD PhD, Samy Lachkar MD (Hôpital Universitaire de Rouen), Margaux Bonnaire, Delphine Gras PhD (Monitoring Team, Hôpital Universitaire de Reims), Philippe Benoit MD (Pharmacie, Hôpital Universitaire de Reims), Sylvain Dukic PhD, Annick Leclainche, Damien Jolly MD PhD (Pôle Recherche-Innovations, Hôpital Universitaire de Reims). These collaborators did not receive any compensation for their contributions. The REVOLENS Study was supported by an academic grant from the French Ministry of Health (Direction Générale de l'Offre de Soins, PSTIC-2012). The coils were purchased from the manufacturer (BTG/PneumRx, Mountain View, CA, USA) which had no involvement in the study design and analysis of the data. PneumRx/BTG provided a financial support for the follow-up assessment after 1 year. The French Ministry of Health had full access to the results of the study, but had no involvement in the design and conduct of the study, collection, management, analysis, and interpretation of data, preparation, review, or approval of the manuscript, and decision to submit the manuscript for publication.

\section{Author contributions}

All authors contributed toward data analysis, drafting and critically revising the paper, gave final approval of the version to be published, and agree to be accountable for all aspects of the work. Gaëtan Deslee had full access to all of the data in the study and takes responsibility for the integrity of data and accuracy of data analysis. Study concept and design was developed by Jeanne Marie Perotin, Gaëtan Deslee, Charles Hugo Marquette, and Coralie Barbe. Data acquisition was performed by Jeanne Marie Perotin, Gaëtan Deslee, Sylvie Leroy, Hervé Mal, Hervé Dutau, Arnaud Bourdin, Jean Michel Vergnon, Christophe Pison, and Charles Hugo Marquette. Data analysis and interpretation were carried out by Jeanne Marie Perotin, Gaëtan Deslee, Charles Hugo Marquette, and Coralie Barbe. Manuscript was drafted by Jeanne Marie Perotin, Sylvie Leroy, Charles Hugo Marquette, and Gaëtan Deslee. Critical revision of the manuscript for important intellectual content was done by Jeanne Marie Perotin, Sylvie Leroy, Charles Hugo Marquette, Hervé Mal, Hervé 
Dutau, Arnaud Bourdin, Jean Michel Vergnon, Christophe Pison, Coralie Barbe, and Gaëtan Deslee. Statistical analysis was carried out by Coralie Barbe. The study was supervised by Gaëtan Deslee.

\section{Disclosure}

Gaëtan Deslee has been involved as an investigator in previous studies sponsored by BTG/PneumRx, and received travel reimbursements and speaker fees for educational sessions and consulting from BTG/PneumRx. Hervé Mal received honorarium from Boehringer, Bayer, Roche, Astellas, Chiesi, Actellion, Pfizer, Novartis, and GlaxoSmithKline outside the submitted work. Hervé Dutau received travel reimbursements and speaker fees for educational sessions and consulting from BTG/PneumRx. Arnaud Bourdin received honorarium from Astra Zeneca, GlaxoSmithKline, Boehringer, Novartis, Teva, Chiesi, Actellion, Gilead, and Roche outside the submitted work. Jean Michel Vergnon received travel reimbursements and speaker fees for educational sessions from BTG/PneumRx. Christophe Pison received honorarium from BTG/PneumRx and his hospital received funds to conduct trials from Holaira, PulmonX, and BTG/PneumRx. Charles Hugo Marquette has been involved as an investigator in previous studies sponsored by BTG/
PneumRx, and received travel reimbursements and speaker fees for educational sessions and consulting from BTG/ PneumRx. The authors report no other conflicts of interest in this work.

\section{References}

1. Gauvain C, Mornex JF, Pison C, et al. Health-related quality of life in patients with alpha-1 antitrypsin deficiency: the French experience. COPD. 2015;12(Suppl 1):46-51.

2. Edgar RG, Patel M, Bayliss S, Crossley D, Sapey E, Turner AM. Treatment of lung disease in alpha-1 antitrypsin deficiency: a systematic review. Int J Chron Obstruct Pulmon Dis. 2017;12:1295-1308.

3. Shah PL, Herth FJ, van Geffen WH, Deslee G, Slebos DJ. Lung volume reduction for emphysema. Lancet Respir Med. 2017;5(2):147-156.

4. Deslée G, Mal H, Dutau H, et al. Lung volume reduction coil treatment vs usual care in patients with severe emphysema: The REVOLENS randomized clinical trial. JAMA. 2016;315(2):175-184.

5. Hartman JE, Ten Hacken NH, Klooster K, Boezen HM, de Greef MH, Slebos DJ. The minimal important difference for residual volume in patients with severe emphysema. Eur Respir J. 2012;40(5):1137-1141.

6. Jones PW. St. George's Respiratory Questionnaire: MCID. COPD. 2005; 2(1):75-79.

7. Gøtzsche PC, Johansen HK. Intravenous alpha-1 antitrypsin augmentation therapy for treating patients with alpha- 1 antitrypsin deficiency and lung disease. Cochrane Database Syst Rev. 2016;9:CD007851.

8. Hillerdal G, Mindus S. One- to four-year follow-up of endobronchial lung volume reduction in alpha-1-antitrypsin deficiency patients: a case series. Respiration. 2014;88(4):320-328.

9. Tuohy MM, Remund KF, Hilfiker R, Murphy DT, Murray JG, Egan JJ. Endobronchial valve deployment in severe $\alpha-1$ antitrypsin deficiency emphysema: a case series. Clin Respir J. 2013;7(1):45-52.
International Journal of COPD

\section{Publish your work in this journal}

The International Journal of COPD is an international, peer-reviewed journal of therapeutics and pharmacology focusing on concise rapid reporting of clinical studies and reviews in COPD. Special focus is given to the pathophysiological processes underlying the disease, intervention programs, patient focused education, and self management protocols.

\section{Dovepress}

This journal is indexed on PubMed Central, MedLine and CAS. The manuscript management system is completely online and includes a very quick and fair peer-review system, which is all easy to use. Visit http://www.dovepress.com/testimonials.php to read real quotes from published authors. 